\title{
LA TEMPORADA TEATRAL DE 1792 EN EL NUEVO COLISEO DE MÉXICO
}

\begin{abstract}
I
Para los monarcas de España el período del gobierno de don Juan Vicente de Güemes Pacheco de Padilla, conde de Revillagigedo, segundo virrey de este título en la Nueva España, coincidió con momentos muy aciagos del siglo xvir. El mismo año de $\mathrm{r} 789$, en que el nuevo vice soberano asumió su prestigioso cargo en México, presenció los actos de la Asamblea Nacional de Francia que presagiaban el rápido desmoronamiento del ancien régime y la aniquilación de su absolutismo y feudalismo. De hecho, éstos fueron actos que hicieron temblar todos los tronos de las dinastías europeas. Antes de aquella fecha se podía afirmar que la idea de insurrección en Hispanoamérica nunca se había manifestado con el objeto de conseguir la separación definitiva de la Península. En las contadas sublevaciones ocurridas en las posesiones ultramarinas hasta entonces, parecía que los naturales no aspiraban sino a mejorar su condición de súbditos o colonos, pues siempre protestaban que no era su intención romper los vínculos que les unían a la Corona Española, ni tampoco negar la lealtad jurada a su Católica Majestad. Pero el conde de Revillagigedo, sin darse cuenta al principio de la tormenta que amenazba, tuvo que hacer frente al comienzo de un movimiento popular que, con el tiempo, había de cundir y culminar en la emancipación política de los reinos americanos de la metrópoli y en la pérdida casi total del grandioso imperio hispánico.

Durante los primeros meses de su administración el animoso virrey creía infundados los temores expresados en la correspondencia del Gobierno de Madrid, y en su carta del 14 de enero de I 790 dirigida a él escribió que:
\end{abstract}

Los miserables indios por naturaleza, por falta de educación, y por la suma pobreza y decadencia en que se hallan no respiran más que humillación y abatimiento ... Sólo una carestía de maíz extraordinaria o unas imposiciones que no pudiesen absolutamente pagar, serían capaces de ponerlos en estado de desesperación que les obligase a emprender algún atentado ${ }^{1}$.

${ }^{1}$ Revillagigedo a Antonio Valdés, México, 14 de enero, 1790, en Precursores 
Todos los demás elementos de la población, añadía Revillagigedo, tenían intereses que les ligaban estrechamente a la soberanía española. Creía él, por lo tanto, que las medidas que se proponía tomar bastarían para anular las preocupaciones de las autoridades madrileñas. El 6 de febrero de 1790 dirigió una carta al Ministro de Hacienda y Guerra, don Antonio Valdés, que contiene una importante declaración que, quizás, ofrezca una clave para comprender la extraordinaria actividad de su administración que la destaca en los anales de la época colonial. Revillagigedo explicó su procedimiento para desvanecer todo temor de rebelión :

El medio que pienso será también muy apropósito para distraer los ánimos y tenerlos ocupados, dando con qué mantenerse a los necesitados, que son los más dispuestos a la revolución, es el emprender obras públicas de común utilidad, comodidad y hermosura; ellas llaman la atención de la gente al paso que las complacen y llenan de satisfacción, y así no ceso de proporcionar los arbitrios y medios de hacer el empedrado, establecer el alumbrado, y conseguir la limpieza de esta ciudad, cuyas obras espero poder comenzar muy pronto ${ }^{2}$.

Una de las primeras reformas de la capital que figuraba en su plan de obras públicas fué la del Nuevo Coliseo de Comedias, que era propiedad del Hospital de Naturales. Casi inmediatamente el virrey puso su cuidado de mejorar el "espectáculo cómico" de este teatro que, en realidad, había vuelto a caer en la mayor postración. Como no había entonces en México cafés ni lugares públicos, según Revillagigedo, donde los ociosos pudieran concurrir para platicar y chismear, y la sociedad se reunía muy poco en casas particulares, la gente solía juntarse, por defecto de otras diversiones de esta índole, en la casa de comedias más para conversar que para gustar las mal representadas obras dramáticas ${ }^{3}$. Para que los espectáculos fuesen más emocionantes, atrayendo así un público aún más numeroso y distrayéndolo de las noticias e ideas de ultramar que pudieran perjudicar el buen orden y sosiego del reino, se emprendió la reforma del edificio del Nuevo Coliseo ${ }^{4}$ y la reorganización de su com-

ideológicos de la guerra de independencia, 1789-1794, México, 1929, Publicaciones del Archivo General de la Nación, vol. I, pág. 6.

2 Revillagigedo a Antonio Valdés, México, 6 de febrero, r79o, ibid., vol. I, pág. I5.

3 Revillagigedo a Antonio Valdés, México, 14 de enero, I79o, ibid., vol. I, pág. 6.

4 En el apéndice de ilustraciones de Artemio de Valle-Arizpe, Calle vieja y calle nueva, México, 1949, se hallan reproducciones de grabados y fotografías del Coliseo Nuevo. Los capítulos de esta curiosa obra titulados La calle del Coliseo, luego del Coliseo Viejo, su portal y su teatro y La calle del Coliseo Nuevo, su teatro y el palacio de De La Borda, brindan al lector una descripción muy viva y detallada del interior y del funcionamiento de este teatro en los tiempos del conde de Revillagigedo. 
pañía de cómicos. Y con el fin de que hubiese el mayor decoro en la buena elección de las obras que se representasen, el virrey nombró un Oidor de la Real Audiencia, don Cosme de Mier y Trespalacios, para el cargo de Juez de Teatro de Comedias, y al padre Ramón Fernández del Rincón para servir de censor de piezas ${ }^{5}$.

Cada año se arrendaba el Coliseo a un asentista en subasta pública, y en I 790 el mejor postor fué un tal Gerónimo Marani. Como no volvió este sujeto a pujar el año siguiente, ni hubo otro postor que pasase de la cantidad de 4,000 pesos por el asiento, Revillagigedo puso manos directamente en la administración del teatro "con tan feliz éxito que el año de I 792 dejó más de i i,00o pesos de ganancia líquida y en el de I 793 más de 9,000 pesos" ${ }^{3}$. A pesar de grandes y continuos disgustos con actores revoltosos y cómicas livianas, y de las intrigas de las bailarinas y cantarinas y mil otros quebraderos de cabeza que afligían constantemente a los asentistas y al mismo virrey, las temporadas de I 790 y de I79 I habían realizado bastante bien el empeño de Revillagigedo en "distraer los ánimos", aunque dejaron de alcanzar el éxito anhelado. En I792 el cariz que tomaban los acontecimientos políticos en Europa y en América era cada vez más amenazador, y el virrey se sentía obligado a tomar medidas aún más enérgicas para que los habitantes de la capital no se enterasen de lo que pasaba. En Francia las cosas andaban de mal en peor, pues la revolución entraba ya en su etapa más violenta y sangrienta. En agosto de este año el proletariado de París se había levantado contra la monarquía liberal, impuesta por fuerza en la familia real un poco antes; y después de unas semanas de anarquía y de carnicería se proclamó una república en septiembre fundada en los "peligrosísimos" principios de la democracia. Antes de finalizar el año incoaba causa contra el rey francés, pariente del monarca español, y poco después este malhadado Borbón fué condenado a ir a la guillotina. La repercusión en España de estos acontecimientos tan funestos para el viejo régimen precipitó la caída del ministerio de Floridablanca y la subida de Aranda, quien, a su vez, se vió sustituído por el joven y apuesto Godoy, favorito de la reina.

Las olas de estas convulsiones sociales y políticas no podían menos de llegar a las costas de América, pese a los esfuerzos realizados por las autoridades para poner un dique a la invasión de ideas tan "disolventes" en las posesiones de la Corona Española. La promulgación de la Declaración de los derechos del hombre en Santo Domingo ya había provocado una guerra civil entre los elementos blancos y mulatos de la sociedad isleña, y los numerosos esclavos negros aprovecharon esta coyuntura para

5 Enrique de Olavarría y Ferrari, Reseña histórica del teatro en México, México, I 895 , vol. I, pág. 85 .

6 Instrucción reservada que el conde de Revillagigedo dió a su sucesor en el mando, marqués de Branciforte sobre el gobierno de este continente en el tiempo que fué su virrey, México, 1831 , pág. 52. 
sublevarse ${ }^{7}$. En la anarquía así producida los europeos de aquella parte de la isla huyeron apresuradamente, buscando asilo en los Estados Unidos y en otras partes. En el Brasil, Joaquim José de Silva Xavier, mejor conocido por el apodo de "Tiradentes", sufrió la pena de muerte en I $79^{2}$ por haber conspirado contra el gobierno portugués, y de todas partes de la América española los virreyes, capitanes generales y otros gobernantes prevenían "que en la cabeza de los americanos comenzaban a fermentar principios de libertad e independencia peligrosísimos a la soberanía de España" ". Ya tenía Revillagigedo sobrada razón para empujar con tesón el programa de obras públicas emprendido antes en la capital y en el reino, incluso el mejoramiento de los espectáculos en el Nuevo Coliseo, cuyo objeto fudamental fué "distraer los ánimos" y divertir a la gente ociosa y descontentadiza de las calles y de los salones de México.

\section{II}

La compañía de comediantes del Nuevo Coliseo $^{9}$ dió un promedio de veintiuna o veintidós representaciones al mes durante la temporada de I 792, según se desprende de los registros incompletos que se hallan en los Papeles del Colegio de San Gregorio conservados en el Museo Nacional de México ${ }^{10}$. Los actores, por lo tanto, se vieron obligados a trabajar cinco o seis días a la semana, representando casi siempre distintas

7 Véase Philip D. Gurtin, The declaration of the Rights of Man in Sainte Domingue, $1788-1792, H A H R$, 30, 1950, págs. 157-1 75.

${ }^{8}$ Guzmán Blanco, Documentos para la historia de la vida pública del Libertador de Colombia, Perú, y Bolivia, Caracas, 1875, pág. 229.

9 "Del 8 de Abril de 1792 al 12 de Febrero de 1793 la Compañía del Real Coliseo de México estuvo así formada: Primera Dama, Antonia de San Martín; Segunda, Marcela Elizundo: Sobresalienta, Josefa González: Primera Graciosa, Teresa Acosta: Segunda, Ana de Castro: Primer Galán, Fernando Gavila (¿autor de la comedia La mexicana en Inglaterra?); Otro, Juan de Lagenheim; Segundo, Miguel Zendejas; Tercero, Nicolás Jaime; Cuarto, Miguel Meneses (el menor): Primer Barba, José Domingo Rosales; Segundo, Gerónimo Guerrero; Primer Gracioso, Juan Moreno; Segundo, Miguel de Ayala; Partes de por medio, Mariano Rozuela, José Duque, Ignacio Vega, Manuel Alanís, Diego Luciano Rodríguez; Primer Apunte, Norberto Inzaurraga; Segundo, Miguel Meneses; Tercero, José Garduño; Guardarropa, Mariano Rivero; Ayudante, Miguel Silva.-Cantores: Primera, Felipa Mercado; $2^{7}$ María Martínez; $3^{7}$ María Loreto Rendón; $4^{7}$ Francisca Montes; $5^{7}$ Matilde Guzmán; $6^{7}$ Rosalía Estrada; Primer Sainetero, Sebastián Guzmán; $2^{\circ}$ Mariano Irízar; $3^{\circ}$ Ignacio Flores; $4^{\circ}$ Mariano Girón.-Bailarines: Gerónimo Marani, su mujer y cuatro hijos; José María Morales; Figurantes, Joaquín Rivera, José Vigueras, Mariano González, Ana Zendejas, Gertrudis Sánchez, Ana Pacheco, Feliciano Espinosa, María Albina; Para cantar y bailar sones del país, José Bonilla.-Pintores, Juan Ignacio Tamayo, Juan Sáenz; Carpinteros, Juan Zúñiga; Peluquero, Antonio Gómez.-Director, Dionisio Vernad". Olavarría y FeRRARI, op. cit., I, págs. I47-I48.

10 Véase el apéndice documental. 
comedias en cada función, aunque de vez en cuando se repetía la misma pieza en días sucesivos o durante la misma temporada. Era ésta la rutina en todos los teatros de la época y apenas variaba de temporada en temporada, si bien se nota una ligera variación en la de 1792 . Dos años antes la serie de comedias era interrumpida con frecuencia por una folla, que se ha definido como " . . la alegre precursora del popular 'género chico', pues estaba compuesta de varios pasos de comedia, conexos entre sí y mezclados con otros de música"11, y por las llamadas "maromas", o ejercicios de volatineros. De éstas hubo cinco y de aquéllas once en la temporada de I790, mientras en la de 1792 no aparece más que una folla y ninguna maroma. Así es que la compañía presentó en el segundo de estos años comedias de tres actos casi exclusivamente.

En otros aspectos la temporada de 1792 ofreció pocas diferencias de las anteriores ${ }^{12}$. La elección de comedias varió lo suficiente para cambiar ligeramente la prioridad de los comediógrafos favoritos que dominaban la escena contemporánea sin que se advirtiera novedad alguna en la predilección universal por una extraña mescolanza de obras románticas, sentimentales, melodramáticas, trágicas, didácticas y costumbristas. Los carteles de México, como los de España y del Perú, denunciaban muy a las claras la confusión estética y el agotamiento artístico del siglo xvIII que habían minado la magnífica tradición dramática de la Península, y ya era patente que la comedia nacional había llegado a su último grado. Como faltaba el espíritu, la forma se agotaba, y los comediógrafos que suministraban las obras representadas estaban, en su mayoría, faltos de sensibilidad poética, originalidad o vitalidad. Una que otra obra de auténtico mérito se ponía en escena, a juzgar por los títulos, si es que no se trataba de puras imitaciones o malas refundiciones. Del Siglo de Oro subsiste Calderón de la Barca como la deidad titular, siendo el maestro más venerado y casi sin rival, pues gran parte del repertorio de la compañía del Nuevo Coliseo se compone de sus obras y las de sus numerosos discípulos. En la temporada de $179^{2}$ descuella su nombre en los carteles que anuncian unas veinte comedias suyas, de las cuales, sin embargo, sólo dos tuvieron repeticiones ${ }^{13}$.

Gozaba de favor casi igual en México este año el autor dramático muy inferior a Calderón, Antonio de Valladares, cuyas obras se representaron dieciséis veces. Aunque el número de títulos de este comediógrafo se reduce a la mitad de los de Calderón, se repitieron cinco de sus comedias una y dos veces. El dramaturgo que ocupó el tercer lugar de preferencia en la jerarquía de favoritos fué José de Cañizares, cuyo amaneramiento en la forma y gongorismo en la parte lírica remedaban dé-

11 Valle-Arizpe, op. cit., pág. 469.

12 Véanse Irving A. Leonard, The 1790 theater season of the Mexico City Coliseo, HR, vol. I9, abril, I95I, núm. 2; The theater season of 1791-1792 in Mexico City, $H A H R$, vol. 3 I, Mayo, I951, núm. 2.

13 Véase el apéndice documental. 
bilmente el estilo de su maestro, Calderón de la Barca. En las catorce representaciones que mereció Cañizares en la temporada de I792, había comedias cuyos asuntos eran patentes imitaciones del teatro calderoniano.

Siguiendo el orden de preferencia y juzgando por la cantidad casi igual de piezas de cada uno puestas en escena, hay un grupo de autores integrado por Pérez de Montalbán, José Concha, Agustín Moreto, Cristóbal Monroy, Tomás Iriarte, Diego Sevilla, Francisco de Leiva, Álvaro Cubillo, Fernando Gavila y otras más. Este cuerpo colectivo y un tanto abigarrado de comediógrafos y de escritores mercenarios simboliza la falta casi total de discernimiento por parte del público finisecular que frecuentaba el Nuevo Coliseo. Ya se habían echado al olvido los grandes nombres del Siglo de Oro como Lope de Vega y Tirso de Molina, exceptuando, desde luego, el de Calderón quien, con su prole de refundidores poetastros, se había enseñoreado del teatro en todo el mundo hispánico. Pero el repertorio de la temporada de 1792 trae una novedad, pues se nota por primera vez en el siglo xvir la inclusión de una obra del clásico dramaturgo nacido en la Nueva España, Juan Ruiz de Alarcón, de quien parecía que apenas se tenía memoria en su país natal. La comedia a que me refiero es El tejedor de Segovia, en dos partes, la segunda de las cuales es de la pluma de Alarcón. No es de extrañar la elección de esta obra, pues su carácter encajaba bien en la manifiesta preferencia del público de fines del siglo xviII y principios del siguiente por dramas de tipo preromántico. Pero en los anales del teatro mexicano colonial se echan de menos las representaciones de las obras más apreciadas de este insigne dramaturgo criollo, y la comedia El tejedor de Segovia, relativamente inferior, es la única, que se sepa, conocida del público de México en los últimos años del coloniaje ${ }^{14}$.

Un repaso de los títulos de comedias que se registran en los Papeles del Colegio de San Gregorio referentes a la temporada de $179^{2}$ del Nuevo Coliseo sugiere uno que otro comentario más. Es curioso notar que Agustín Moreto, cuyas obras en las temporadas inmediatamente anteriores habían gozado de mucha popularidad, colocando a su autor, de hecho, al lado de su maestro, Calderón, ocupó un puesto muy inferior en la de I792, cosa que se explica sin duda más por la casualidad que por la intención. De interés también es la representación en cuatro ocasiones de una comedia titulada La mexicana en Inglaterra por un autor casi desconocido, llamado Fernando Gavila ${ }^{15}$. Muy del gusto de los que asistían a los coliseos, tanto en España como en los virreinatos, eran las

14 La erudita Dorothy Sahons declara en su interesante artículo Alarcón's reputation in Mexico, $H R$, vol. 8, abril, 1940, págs. 139-144, que la primera representación en la Nueva España de una comedia de Alarcón tuvo lugar en la temporada teatral de 1805-1806, y que fué esta obra El tejedor de Segovia (pág. I43).

15 Véase el apéndice documental, septiembre 16,20 y 21 ; octubre 5. Posiblemente el primer galán de la compañía del Nuevo Coliseo fué el autor. 
comedias de magia que se repetían con frecuencia. En México las más populares eran La fuente de la judía de Monroy, y Marta la Romarantina de Cañizares ${ }^{16}$. Estos melodramas, en que intervenía el Diablo, eran la singular preferencia de "... las criadas, los sirvientes, los niños, y otras gentes de la más descuidada educación ..."17

Pero el Nuevo Coliseo no dejó de ofrecer a sus abonados obras meritorias de autores nacionales y traducciones o refundiciones de comedias excelentes por dramaturgos franceses e italianos. Entre estos escritores más hábiles se halla Ramón de la Cruz, aunque sus tragedias y refundiciones de piezas ajenas predominaban sobre sus justamente famosos sainetes, que constituían las mejores fuentes y documentos para la historia interna en el último tercio del siglo xviri. Nuevas brisas empezaban poco a poco a soplar por el teatro español en las repetidas representaciones de El viejo y la niña de Moratín ${ }^{18}$, que se acababa de estrenar en Madrid en I 79o, y de $E l$ señorito mimado por el fabulista Iriarte, que fustigaba en esta obra los defectos de la educación ${ }^{19}$. La versión castellana hecha por Iriarte con el título $E l$ filósofo casado de la comedia francesa de Nericault Destouches tuvo el honor, un tanto excepcional en México, de ponerse en escena cuatro veces en la temporada de $1792^{20}$. Y se anunciaban en los carteles dramas, vertidos al español, de Molière ${ }^{21}$, Beaumarchais $^{22}$ y Jean Baptiste de Rousseau ${ }^{23}$; pero de mayor aceptación aún en el Nuevo Coliseo eran las obras de autores italianos. De éstos sobresalía Carlo Goldoni, quien de hecho rivalizaba con los mejores comediógrafos españoles en la popularidad de sus comedias de costumbres, aunque digamos de paso que en la temporada de $179^{2}$ esta popularidad del insigne italiano no queda tan establecida como en las anteriores. Disfrutaban de una acogida bastante calurosa por estos años en México las obras de Metastasio, cuya tragedia La Celmira ${ }^{24}$, traducida al español por el peruano Pablo de Olavide, se repitió tres veces en I792. De vez en cuando un compatriota, Apóstolo Zeno, contribuía con una pieza al repertorio de la compañía del Nuevo Coliseo ${ }^{25}$.

En los meses de agosto y septiembre parece que se solían representar

16 Véase el apéndice mayo 7, 8, 9; julio 9, ro y 30, 31 ; diciembre 23.

17 Ada M. Coe, Catálogo bibliográfico y crítico de las comedias anunciadas en los periódicos de Madrid desde 1661 hasta 1819, Baltimore, 1935, The Johns Hopkins Studies in Romance Languages and Literatures, extra volume 9, pág. I43.

18 Véase el apéndice julio I 2, noviembre II.

19 Véase el apéndice noviembre 8.

20 Véase el apéndice mayo 30 y 31 ; agosto 16 ; diciembre 27.

21 Véase el apéndice julio 2.

22 Véase el apéndice junio 17 y 21.

23 Véase el apéndice junio 19.

24 Véase el apéndice junio 7, julio I y octubre 7. De interés es el estudio de Sterling A. Stoudemire, Metastasio in Spain, $H R$, vol. 9, I941, núm. I, págs. I84-191.

${ }_{25}$ Véase el apéndice mayo 17. 
varias comedias en que intervenía la figura de Hernán Cortés, o que versaban sobre las famosas hazañas del sitio y rendición de Tenochtitlán por el gran conquistador y sus soldados. En I 790 se le había ocurrido al conde de Revillagigedo, siempre alerta a novedades que distrajesen los ánimos de los habitantes de la Nueva España y que les recordasen las glorias de la metrópoli, que convendría desenterrar los restos del esclarecido Cortés para trasladarlos al Hospital de Jesús Nazareno, fundado y dotado por el conquistador en la capital. Ya se gestionaba la traslación en I 792, contratando un monumento imponente y encargando a Manuel Tolsá, recién llegado a México, un busto de bronce dorado a fuego. Y, efectivamente, después de largos trámites, se depositó la urna con los restos de Cortés en la iglesia de Jesús Nazareno en julio de I 794, y el 8 del mismo mes el fraile dominico Servando Teresa de Mier, que se haría famoso después, predicó un sermón en las honras fúnebres celebradas en esta ocasión ${ }^{26}$.

Por malo que fuera el gusto de los espectáculos del Nuevo Coliseo en aquella temporada de 1792 , conviene recordar que las mismas obras dramáticas que divertían a los habitantes de México se representaban también, y casi simultáneamente, en los teatros de la Cruz y del Príncipe de Madrid y en los de Lima, como se comprueba por un cotejo de los títulos que ostentaban los carteles de sus respectivas funciones ${ }^{27}$. De esto se deduce que el teatro virreinal se hallaba a la misma altura que el de la metrópoli, por lo que se refiere a la elección de piezas; y si el gusto de los súbditos de ultramar de la Corona Española parecía bastante estragado, respondía infaliblemente a la nulidad de los comediógrafos de la Península y a la postración del teatro barroco. Si los espectáculos en España aventajaban en algo a los de las colonias en esta época, fué exclusivamente obra de una serie de actrices y actores que se sucedieron en las tablas peninsulares desde 1760 hasta comienzos del siglo xix. Allí cómicas de la talla de María Ladvenant, María del Rosario Fernández, o sea "La Tirana", e Isidoro Máiquez, que eran a la vez recitadores, cantantes y danzarines, lograron dar cierta vitalidad al teatro barroco y lo hicieron popularísimo ${ }^{28}$. El Coliseo de Lima tuvo a "La Perricholi", pero el de México, en este aspecto, fué menos afortunado. Sin embargo, no por esto dejaron los espectáculos del Nuevo Coliseo, fomentados por el enérgico Revillagigedo, de cumplir con su deseo, en parte a lo menos, de "distraer los ánimos" y apartarlos de las ideas tan "disolventes" de la democracia

26 Véase Francisco de la Maza, Los restos de Hernán Cortés, CuA, año 6, marzo-abril, 1947, págs. 153-174; Irving A. Leonard, Cortés' remains - and a document, $H A H R$, vol. 28 , I948, núm. I, págs. 53-61.

${ }^{27}$ Este cotejo se puede realizar con la obra de ADA M. CoE, citada en la nota I 7 arriba, y con Irving A. Leonard, El teatro en Lima, 1790-I793, HR, vol. 8, I940, núm. 2, págs. 93-1 12. passim.

${ }^{28}$ José OrTEga y Gasset, Papeles sobre Velázquez y Goya, Madrid, 1950, 
que empezaban a propagarse por el mundo atlántico en los últimos años de la décima octava centuria.

IRVING A. LEONARD

University of Michigan.

Comedias que se representaron en el Mes de Abril de $1792^{29}$

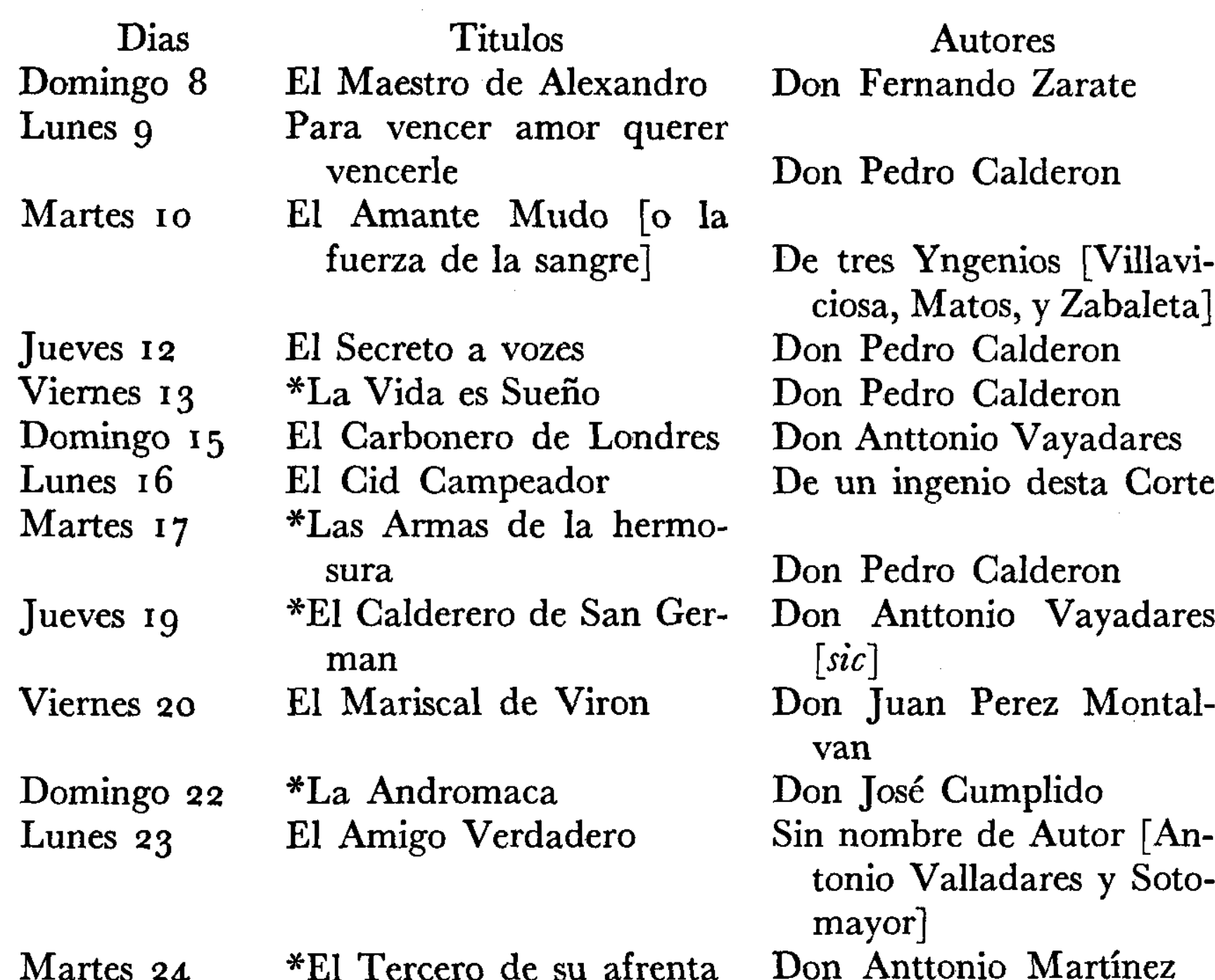

Martes 24 *El Tercero de su afrenta Don Anttonio Martínez

${ }^{29}$ Las siguientes listas de comedias representadas en el Coliseo Nuevo desde el 8 de abril hasta el 31 de diciembre de $179^{2}$ se hallan en los Papeles del Colegio de San Gregorio, vol. I5 I, conservados en el archivo del Museo Nacional de México, de los cuales poseo copias fotográficas. Al hurgar en estos papeles no logré dar con las listas que corresponden a las últimas semanas de la temporada de r 792 y 1793 , o sea, las de enero y la primera mitad de febrero de 1793. En algunos casos hemos ampliado el título de las comedias y hemos procurado identificar los nombres de autores que faltan en las listas, poniendo estos datos entre corchetes. Para estas identificaciones consultamos las siguientes obras: AdA M. CoE., op. cit.; Cayetano A. de la Barrera y Leirado, Catálogo bibliográfico y biográfico del teatro antiguo español desde sus orígenes hasta mediados del siglo xviii; Francisco Medel del Castillo, Indice general alfabético de todos los títulos de comedias, Madrid, 1735, reimpreso por John M. Hill en la $R H i$, vol. 65, 1929, págs. 144-369; y la lista de comedias y dramaturgos recopilada por Moratín en la $B A A E E$, vol. 2.

* Los títulos señalados con asterisco se refieren a comedias representadas en el mismo año de 1792 en los teatros de la Cruz y del Príncipe, de Madrid. 
Jueves 26

Viẹrnes 27

Domingo 29

Lunes 30

Mayo $1^{\circ} / 92$
Competidor hijo y Padre El falso Nuncio de Portugal

El Buen Hijo

No hay contra lealtad Cautelas
Don José Cañizares

De un ingenio desta Corte [José Cañizares]

Don Anttonio Vayadares

Don francisco de Leiva

Dionisio Bernad

Comedias que se representaron en el Mes de Mayo de 1792

Dias

Martes $\mathbf{I}^{\mathbf{0}}$

El Criado de 2 Amos

Jueves 3

La Viuda Subtil

Viernes 4

*No puede ser guardar una Muger

Domingo 6

El Esclavo en grillos de oro

$\left.\begin{array}{l}\text { Lunes } 7 \\ \text { Martes 8 } \\ \text { Miercoles } 9\end{array}\right\}$

Jueves Io

Viernes I I

Domingo 13

Lunes 14

Martes I5

Jueves 17

Viernes I 8

Domingo 20

Lunes 21

Martes 22

Jueves 24

Viernes 25

Domingo 27

Lunes 28

Martes 29
La fuente de la Judia

Las Ylustres Roncalesas

*El Castigo de la miseria

* La Zayda

\section{*Ydem}

* La Presumida y la hermosa

El Severo Dictador [y vencedor delincuente, Luno Papirio y Quinto Fabio] La fuerza del natural

* La Andromaca y $2^{a}$ parte

El vinatero de Madrid Reynar después de morir *E1 Elector de Saxonia * El Defensor de su agravio La vanda y la flor
El Rayo de Andalucia, I ${ }^{a}$
Autores

Don José Concha [tr. de Goldoni?]

Sin nombre de Autor [Carlo Goldoni]

Don Agustin Moreto

Don Francisco Bances Candamo

Don Cristoval Monrroy

Don Luis Monzin

Don Juan de la $\mathrm{Hoz}$

Sin nombre de Autor [Juan Francisco Tudó]

Don Fernando de Zarate Sin nombre de Autor [Apostolo Zeno, trad. por Ramón de la Cruz]

Don Agustin Moreto

Don José Cumplido

Don Albaro Cubillo

Don Anttonio Vayadares

Don Luis Coello

Don Luis Monzin

Don Agustin Moreto

Don Pedro Calderon 
Miercoles $30 \quad *$ El filosofo casado

Jueves $3 \mathbf{I} \quad$ *Ydem

Mexico, Mayo $3^{1 / 92}$
Sin nombre de Autor [Tomás de Iriarte]

Comedias que se representaron en el Mes de Junio de 1792

Dias

Domingo $I^{9}$

Lunes 4

Martes 5

Jueves 7

Viernes 8

El honor da Entendimiento

Domingo Io

$$
\text { La Jarr }
$$
rra

Lunes I I

*El Principe Tonto

Martes I 2

El Pastelero del Madrigal

Miercoles 13 La más constante Muger

Jueves I4 La Viuda Subtil

Domingo I 7 *La Eugenia

Lunes i 8 Los empeños de un acaso

Martes I9 El Hipocondrico

Jueves $21 \quad$ *La Eugenia

Viernes 22 *El Amo Criado

Domingo 24 El huerfano Yngles [o el Evanista]

Lunes 25

Ydem

Martes $26 \quad 2$ El Texedor de Segovia $I^{\text {a }}$

Miercoles 27 y 2 ${ }^{\text {a }}$ Parte

Viernes 29 El buen hijo

Julio $2 / 92$
Dionisio Bernad
Autores

Don Cristoval Monrroy

De un ingenio desta Corte [José Cañizares]

Sin nombre de Autor [Metastasio, trad. por Pablo de Olavide]

Don José Cañizares

Don Francisco Banzes Candamo

Don Francisco de Leyva

De un ingenio desta Corte [Jerónimo Cuellar]

Don Juan Perez Montalvan

Sin nombre de Autor [Carlo Goldoni]

Don Ramon de la Cruz

Don Pedro Calderon

Sin nombre de Autor [Jean Baptiste de Rousseau]

Don Ramon de la Cruz

Don Francisco de Roxas

Sin nombre de Autor [Tomás de Iriarte]

Don Juan de Alarcon

Don Anttonio Vayadares

Dionisio Bernad 
Comedias representadas en el Mez de Julio de 1792

\begin{tabular}{|c|c|c|}
\hline Dias & Titulos & Autores \\
\hline Domingo $I^{\circ}$ & ${ }^{*}$ La Celmira & $\begin{array}{l}\text { Sin nombre de Autor [Me- } \\
\text { tastasio, trad. por Pablo } \\
\text { de Olavide] }\end{array}$ \\
\hline Lunes 2 & El Enferm $\sim$ Ymaginario & $\begin{array}{l}\text { Ydem [Molière, trad. por } \\
\text { Joaquín de San Pedro, o } \\
\text { Manuel Iparraguirre] }\end{array}$ \\
\hline Martes 3 & Cada uno para sí & Don Pedro Calderon \\
\hline Jueves 5 & El Valiente Justiciero & Don Agustin Moreto \\
\hline Viernes 6 & El Principe Prodigioso & $\begin{array}{l}\text { Ydem [y Juan Matos y } \\
\text { Fragoso] }\end{array}$ \\
\hline Domingo 8 & $\begin{array}{l}\text { Combates de amor y honor } \\
\text { entre Padre hijo y Mu- } \\
\text { ger }\end{array}$ & Sin nombre de Autor \\
\hline $\left.\begin{array}{l}\text { Lunes } 9 \\
\text { Martes Io }\end{array}\right\}$ & $\begin{array}{l}\text { Marta la Romarantina } \mathrm{I}^{\mathrm{a}} \\
\text { parte }\end{array}$ & $\begin{array}{l}\text { De un ingenio desta Corte } \\
\text { [José Cañizares] }\end{array}$ \\
\hline Jueves 12 & *El Viejo y la Niña & $\begin{array}{c}\text { Sin nombre de Autor } \\
\text { [Leandro F. Moratín] }\end{array}$ \\
\hline Viernes I 3 & $\begin{array}{l}\text { *Tambien la afrenta es Ve- } \\
\text { neno }\end{array}$ & $\begin{array}{l}\text { De tres Yngenios [Vélez de } \\
\text { Guevarra, Coello, Ro- } \\
\text { jas] }\end{array}$ \\
\hline Domingo 15 & *El Parecido de Rusia & $\begin{array}{l}\text { Sin nombre de Autor [An- } \\
\text { tonio de Castillo] }\end{array}$ \\
\hline Lunes I 6 & El Sacrificio de Yfigenia & $\begin{array}{l}\text { Sin nombre de Autor [José } \\
\text { Cañizares] }\end{array}$ \\
\hline Martes I 7 & *El Hablador & Ydem [Carlo Goldoni] \\
\hline ieves I9 & El Sacrificio de Ifigenia & Ydem [José Cañizares] \\
\hline $\begin{array}{l}\text { Viernes } 20 \\
\text { Domingo } 22\end{array}$ & $\begin{array}{l}\text { El Sabio en su retiro } \\
\text { No hav contra un Padre }\end{array}$ & Don Juan Matos fragoso \\
\hline & razon & Don Francisco de Leiva \\
\hline Lunes 23 & El Sastre del Campillo & $\begin{array}{l}\text { Don Francisco Banzes } \\
\text { Candamo }\end{array}$ \\
\hline $\begin{array}{l}\text { Miercoles } 25 \\
\text { Jueves } 26\end{array}$ & $\{$ El Silano & Sin nombre de Autor \\
\hline Viernes 27 & *El Combidado de Piedra & Don Jose Zamora \\
\hline Domingo 29 & El Tetrarca de Jerusalem & Don Pedro Calderon \\
\hline $\left.\begin{array}{l}\text { Lunes } 30 \\
\text { Martes } 31\end{array}\right\}$ & $\begin{array}{l}\text { Marta la Romarantina } 2^{\mathrm{a}} \\
\text { parte }\end{array}$ & $\begin{array}{l}\text { De un ingenio desta Corte } \\
\text { [José Cañizares] }\end{array}$ \\
\hline Agosto $1^{\circ} / 9^{2}$ & \multicolumn{2}{|c|}{ Dionisio Bernad } \\
\hline
\end{tabular}


Comedias que han de representarse en el Mez de Agosto de [ I 7]92

$$
\text { Dias Titulos Autores }
$$

Jueves 2 El Pricionero de Guerra Don Carlos Goldoni

Viernes $3 \quad$ No siempre lo peor es cierto

Don Pedro Calderon

Domingo 5$\}$

*Ernan Cortes en Tabasco

Don Fermin del Rey

Lunes 6

El Galan fantasma

Don Pedro Calderon

Jueves 9

Cortes Triunfante en Tlascala

Don Agustin Cordero

Viernes 10$\}$

El hijo de quatro Pàdres

Sin nombre de Autor [Pedro Jiménez]

Lunes 13 La Conquista de Mexico

Don Diego Sevilla

Miercoles I5 Las Valientes Amazonas

Jueves $16 \quad{ }^{*}$ El filosofo casado

Don Anttonio Solis

\section{Viernes 17}

Domingo I 9

El Picarillo en España

Sin nombre de Autor [Tomás Iriarte]

Don Jose Cañizares

Lunes 20
Martes 2 I

Derramar su propia Sangre en defensa de su Rey

Jueves 23

La Conquista de Mexico

Don Luis Monzín

Viernes 24

El Domine Lucas

Don Diego Sevilla

Sabado 25

El Suceso de Castilla

Don José Cañizares

Domingo 26 [sic]

Martes 28

Las Ylustres Vivanderas

Don Pedro Calderon

Miercoles 29

No hay burlas con el amor

Jueves 30

El Conde Alarcos

Don Anttonio Vayadares

Don Pedro Calderon

Viernes 3 I

*E1 Licenciado Vidriera

Doctor Mira de Mesqua

Don Agustin Moreto

Amor honor y Poder

Don Pedro Calderon

Julio I I $/ 92$

Dionisio Bernad

Comedias que se representaron en el Mez de Septiembre de 1792

\section{Dias}

Sabado I ${ }^{\circ}$

Domingo 2

Lunes 3

Martes 4

Jueves 6

Sabado 8
Titulos

La Conquista de Mexico fuego de Dios en el querer bien

La Conquista de Mexico

* La Cisma de Ynglaterra

*E1 Principe Tonto

Los Aspides de cleopatra
Autores

Don Diego Sevilla

Don Pedro Calderon

Don Diego Sevilla

Don Pedro Calderon

Don francisco de Leyva

Don francisco de Rojas 
Domingo 9 *El Calderero de San German

Don Anttonio Vayadares

$\left.\begin{array}{l}\text { Lunes io } \\ \text { Martes i I }\end{array}\right\}$

La Conquista de Mexico

Jueves I 3

*El Hablador

Viernes 14

Mudanzas de la fortuna

Domingo 16

La Mexicana en Ynglaterra

Don Diego Sevilla

Sin nombre de Autor [Carlo Goldoni]

Don Cristoval Monrroy

Lunes 17

El Pricionero de Guerra

Fernando Gavila

Martes I8

El Falso Nuncio de Portugal

Don Carlos Goldoni

De un ingenio desta Corte [José Cañizares]

Jueves 20 $\}$ La Mexicana en Ynglate-

Viernes 21 rra

Fernando Gavila

Domingo 23

A Secreto agravio Secreta venganza

Don Pedro Calderon

Lunes 24

Las Ylustres Vivanderas

Martes 25

Jueves 27

Sabado 29 E1 Pleito de Ernan Cortes * Mas sabe el Loco en su Casa que el cuerdo en la agena

Domingo $30 \quad$ El Secreto a vozes

Don Anttonio Vayadares

Don Cristoval Monrroy

Octubre 2/92

Dionisio Bernad

Comedias representadas en el Mez de Octubre de 1792

\begin{tabular}{ll}
\multicolumn{1}{c}{ Dias } & \multicolumn{1}{c}{ Titulos } \\
Lunes I $^{\circ}$ & *Afectos de Odio y amor \\
Miercoles 3 & Federico $2^{\circ}$ Rey de Prucia \\
Jueves 4 & Luis I 4, el grande
\end{tabular}

Viernes 5 La Mexicana en Ynglaterra

Domingo 7 *La Celmira

Lunes 8

Martes 9 Jueves II
Antes que todo es el Rey El Carbonero de Londres
Autores

Don Pedro Calderon

Don Anttonio Vayadares

Don Luciano francisco Comella

Fernando Gavila

Sin nombre de Autor [Metastasio, trad. de Pablo Olavide]

La Prudencia en la Niñez De un ingenio desta Corte [Antonio Pablo Fernández]

Don José Concha

Don Anttonio Vayadares 
Viernes 12 Tambien hay duelo en las

\begin{tabular}{|c|c|c|}
\hline & Damas & Don Pedro Calderon \\
\hline Domingo I 4 & $\begin{array}{l}\text { El Perseguido (Años del } \\
\text { Principe de Asturias, } \\
\text { Nuestro Señor que Dios } \\
\text { guarde) }\end{array}$ & Sin nombre de Autor \\
\hline Lunes 15 & El Conde de Saldaña & Don Albaro Cubillo \\
\hline Martes 16 & $\begin{array}{l}\text { *E1 Sol de España en su } \\
\text { Oriente }\end{array}$ & Don Luis Monzin \\
\hline Jueves i 8 & El Perseguido & Sin nombre de Autor \\
\hline Viernes I9 & El Sordo y el Montañez & Don Melchor Fernández \\
\hline Domingo 21 & *La Magdalena Cautiva & Don Anttonio Vayadares \\
\hline Lunes 22 & El negro del cuerpo blanco & $\begin{array}{l}\text { De un ingenio desta Corte } \\
\text { [Francisco de Leiva Ra- } \\
\text { mírez] }\end{array}$ \\
\hline Martes 23 & El Cid Campeador & Ydem \\
\hline Jueves 25 & *La Magdalena Cautiva & Don Anttonio Vayadares \\
\hline Viernes 26 & Folla & \\
\hline Domingo 28 & El Principe Constante & Don Pedro Calderon \\
\hline Lunes 29 & E1 Mariscal de Viron & $\begin{array}{l}\text { Don Juan Perez Montal- } \\
\text { van }\end{array}$ \\
\hline Martes 30 & La fuerza del natural & Don Agustin Moreto \\
\hline Noviembre I & & nisio Bernad \\
\hline
\end{tabular}

Comedias que se representaron en el Mez de Noviembre de 1792

\begin{tabular}{|c|c|c|}
\hline Dias & Titulos & Autores \\
\hline Jueves $I^{\circ}$ & El hechizado por fuerza & Don Anttonio Zamora \\
\hline Domingo 4 & $\begin{array}{l}\text { * [Emperador] Alberto I }{ }^{\circ} \\
\text { [y la Adelina] (Dias de } \\
\text { su Magestad que Dios } \\
\text { guarde) }\end{array}$ & Don Anttonio Vayadares \\
\hline Lunes 5 & $\begin{array}{l}\text { La mayor hazaña de Car- } \\
\operatorname{los} V\end{array}$ & Don francisco Encizo \\
\hline Martes 6 & La incognita & Don Carlos Goldoni \\
\hline Jueves 8 & El Señorito mimado & Don Tomas Yriarte \\
\hline Viernes 9 & La más constante Muger & $\begin{array}{l}\text { Don Juan Perez Montal- } \\
\text { van }\end{array}$ \\
\hline Domingo I I & ${ }^{*}$ El Viejo y la Niña & $\begin{array}{c}\text { Sin nombre de Autor } \\
\text { [Leandro F. Moratín] }\end{array}$ \\
\hline Lunes I 2 & $\begin{array}{l}\text { De dos enemigos haze el } \\
\text { amor } 2 \text { Amigos (Años de } \\
\text { Su Magestad, que Dios } \\
\text { guarde) }\end{array}$ & Don Gaspar Zabala \\
\hline
\end{tabular}


Martes 13

Jueves I 5

Viernes 16

Domingo 18

Lunes 19

Martes 20

Jueves 22

Viernes 23

Domingo 25

Lunes 26

Martes 27

Jueves 29

Viernes 30 repeticion de dicha

Un Bobo haze ciento

La Viuda Subtil

La Lindona de Galicia

El postrer duelo de España

*Los amantes de Teruel

La posadera [feliz o el enemigo de las mugeres]

El Maestro de Alexandro

La Jacoba

El Verdadero buen hijo

El mejor Par de los doze

Las Victimas del Amor

La Real Jura de Artaxerges
Ydem

Don Anttonio Solis

Don Carlos Goldoni

Don Juan Perez Montalvan

Don Pedro Calderon

Don Juan Perez Montalvan

Sin nombre de Autor [Carlo Goldoni]

Don Fernando Zarate

Don Gaspar Zabala

Don Anttonio Vayadares

Don Juan Perez Montalvan

Don Gaspar Zabala

Don Anttonio Bazo

Diciembre $I^{\circ} / 92$

Dionisio Bernad

Comedias que se representaron en el Mes de Diciembre de ( 17 ) 92

\begin{tabular}{|c|c|c|}
\hline Dias & Titulos & Autores \\
\hline Domingo 2 & ${ }^{*}$ La Zayda & $\begin{array}{l}\text { Sin nombre de Autor } \\
\text { [Juan Francisco Tudó] }\end{array}$ \\
\hline Lunes 3 & $\begin{array}{l}\text { Para vencer amor querer } \\
\text { vencerle }\end{array}$ & Don Pedro Galderon \\
\hline Martes 4 & El Amante mudo & $\begin{array}{l}\text { De tres ingenios [Villavi- } \\
\text { ciosa, Matos, y Zabale- } \\
\text { ta] }\end{array}$ \\
\hline Jueves 6 & Dar la Vida por su Dama & Don francisco de Rojas \\
\hline Sabado 8 & Los Tres Mellizos & Sin nombre de Autor \\
\hline Domingo 9 & $\begin{array}{l}\text { El Premio de la humani- } \\
\text { dad (Años de la Reyna } \\
\text { Nuestra Señora (que } \\
\text { Dios guarde) }\end{array}$ & \\
\hline Lunes io & La Morbella & Fernando Gavila \\
\hline Miercoles I 2 & El Sacrificio de Ifgenia & $\begin{array}{l}\text { Sin nombre de Autor [Jo- } \\
\text { sé Cañizares] }\end{array}$ \\
\hline Jueves I 3 & El Criado de dos amos & Don José Concha \\
\hline 诖 & $\begin{array}{l}\text { * Mentir y mudarse a un } \\
\text { tiempo }\end{array}$ & Don Jose Cordova \\
\hline
\end{tabular}


Domingo i 6 *Más sabe el Loco en su Casa, que el cuerdo en la agena, y natural Viscaino

Don José Concha

$\left.\begin{array}{l}\text { Lunes I7 } \\ \text { Martes I8 } \\ \text { Jueves 20 }\end{array}\right\}$

El Rayo de Andalucía

Don Albaro Cubillo

Viernes 21

Los Tres Mellizos

Sin nombre de Autor

Domingo 23

*El Castigo de la Miseria

Martes 25

La fuente de la Judia

Don Juan de la $\mathrm{Hoz}$

Don Cristoval Monrroy

El Excelentísimo Señor Conde de Perelada

Miercoles 26 El Catolico Recaredo

Don Anttonio Vayadares

Jueves 27

*El Filosofo Casado

Viernes 28

El Riquimero Rey de Gocia

Sin nombre de Autor [Tomás de Iriarte]

Domingo 30 Aristomenes Mesenio

Lunes $3^{1}$

El Mustafá

Ydem

Don Juan Matos

Don José Concha

Enero ${ }^{\circ} / 93$

Dionisio Bernad 